\title{
MULTIPLE MALIGNANT MELANOMATA OF THE UVEAL TRACT IN ONE EYE*†
}

\author{
BY \\ R. A. CONDON AND JOAN MULLANEY \\ From the Department of Ophthalmology, Waterford Regional Health Authority, and the National Ophthalmic \\ Pathology Laboratory and Registry of Ireland, Royal Victoria Eye and Ear Hospital, Dublin
}

THE literature on malignant melanoma of the uveal tract is extensive but case reports of multiple malignant tumours of this type are infrequent. Freckles and naevi are present in approximately 50 per cent. of normal eyes and "are even more frequent and larger in eyes which also contain malignant melanoma of the uveal tract" (Hogan and Zimmerman, 1962). According to Reese (1956), when the malignant melanoma was present in the choroid an associated benign melanoma in the iris occurred in 7.5 per cent. of cases; when the malignant melanoma was primary in the iris or ciliary body, the association was seen in approximately 20 per cent. of cases.

The presence of several malignant pigmented neoplasms could be explained either by the demonstration of metastatic dissemination from a single primary growth or by postulating independent multifocal origins. Reese (1956) stated: "I have seen only one instance of an implantation lesion on the iris from a malignant melanoma of the choroid". Reese (1963) observed that he knew of no authenticated case on record of multiple primary neoplasms of the choroid in a single eye. Rosen and Moulton (1953) reported a case of multiple malignant melanomata of the uveal tract proved by serial section; they described a malignant melanoma of the ciliary body, multiple malignant melanomata of the choroid, and a benign melanoma of the choroid, but published no histological photographs. Frayer (1956) presented a case of malignant melanoma of the iris and ciliary body and a second choroidal melanoma, at a meeting of the Faculty of Ophthalmology of the College of Physicians, Philadelphia; these tumours were considered to have arisen independently of each other.

The present paper describes three separate uveal melanomatous tumours, two of them malignant, in a single eye.

\section{Case Report}

A man aged 65 years was admitted to the ward with severe pain in the left eye. A large intraocular tumour was obvious with retinal vessels clearly visible on its surface. The eye was in a state of acute glaucoma, quite dark to transillumination.

* Received for publication July 11 th, 1966

* Received for publication July 11th, 1966. Hospital, Dublin 2. 
There were two pigmented melanomata (or naevi) on the iris in its lower third, the one on the right near 6 o'clock being blacker than the other. There was no disturbance of the adjacent iris structure to suggest that either of these 'spots' had become enlarged and as far as could be seen there was no structural continuity between any two of the three areas under observation, i.e. they appeared to be distinct entities.

Pathological Report.-Macroscopic examination shows a collapsed left eye. There are two pigmented areas on the iris at 3 and 6 o'clock. The specimen does not transilluminate. The opened globe shows anterior and posterior synechiae. There is a "dumb-bell" shaped black tumour extending across the posterior pole with funnel detachment and sub-retinal serous

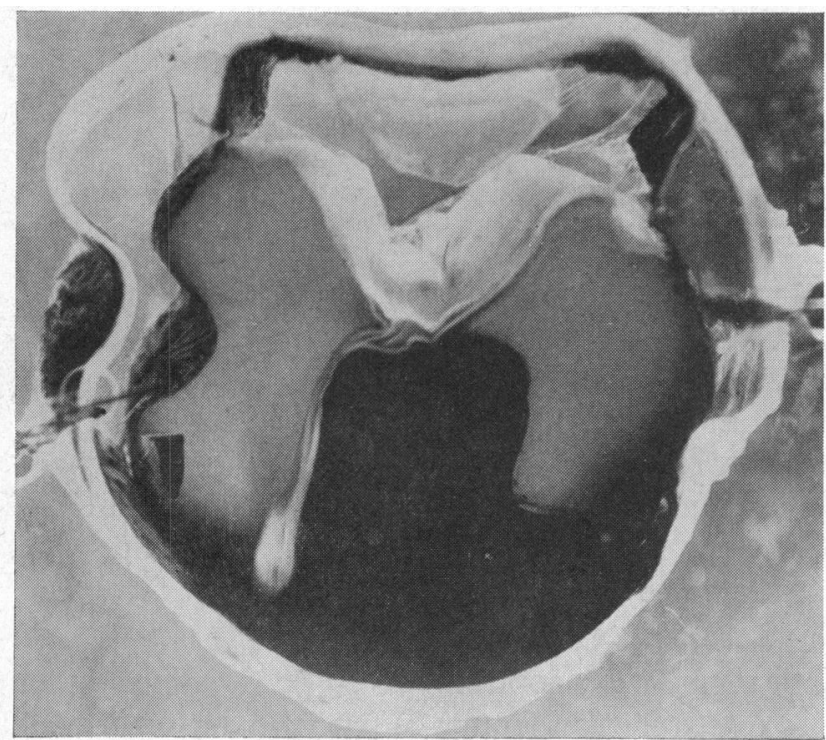
exudation (Fig. 1).

Fig. 1.-Gross view of whole eye with particular reference to posterior choroidal melanoma. Choroidal detachment due to artefact.

Microscopic examination shows nothing remarkable in the cornea. One filtration angle is open and unremarkable while the other is obscured by heavily pigmented cells. Sections made at the level of the melanoma seen at 6 o'clock show it to be a deeply pigmented spindle-cell tumour of the iris, arising centrally and anterior to the sphincter muscle (Fig. 2, and Fig. 3, opposite).

FIG. 2.-Melanoma seen at 6 o'clock. No extension along iris at this level. Haematoxylin and eosin $\times 12 \cdot 5$.

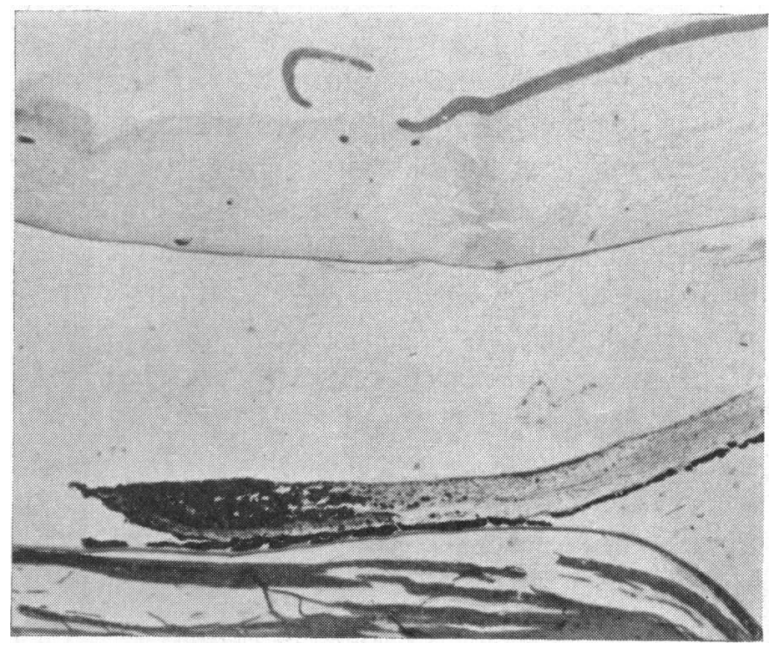

It is infiltrating the angle, the meshwork, and the anterior part of the ciliary body (Fig. 4, opposite), and some of the cells are tracking along Descemet's membrane. The lesion lies 


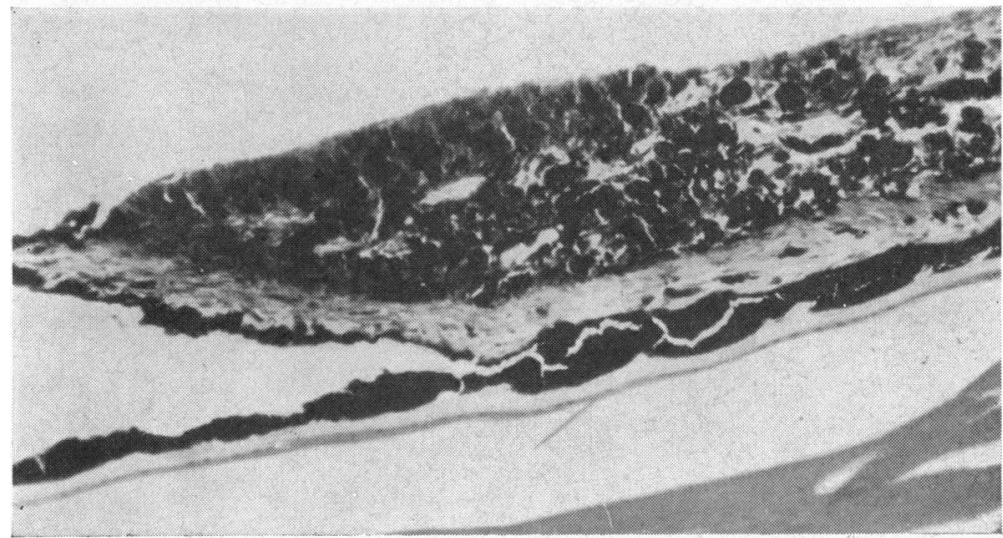

FIG. 3.-As in Fig. 2, but showing situation anterior to sphincter muscle and a posterior synechia. Haematoxylin and eosin. $\times 50$.

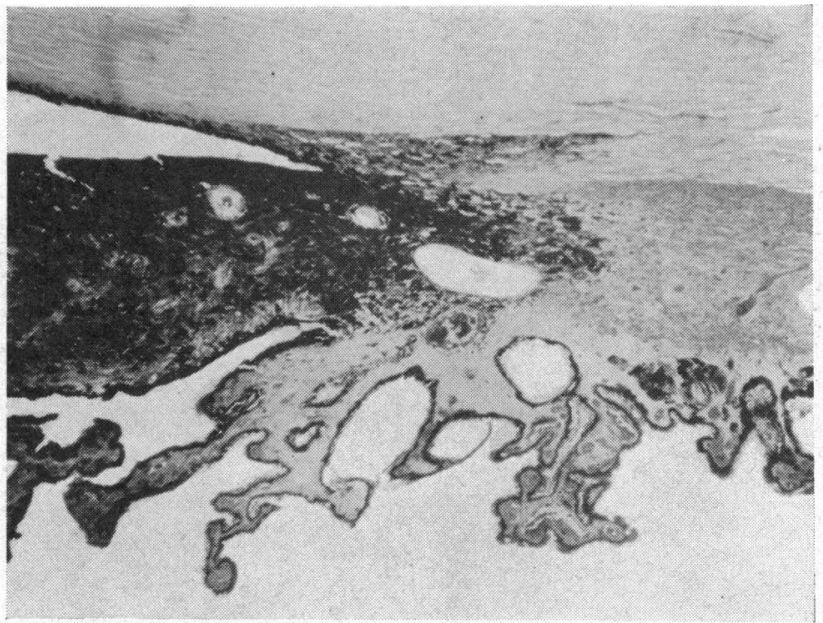

FIG. 4.-As in Fig. 2, but showing extension along iris to involve the angle. Haematoxylin and eosin. $\times 12 \cdot 5$.

anterior to, and distinct from, the pigment epithelium of the iris throughout its length. This neoplasm has been classified as malignant because of the cell type and the evidence of infiltration.

The second pigmented iris lesion seen at 3 o'clock is a benign melanoma localized, but anterior to, the sphincter muscle and associated with ectropion (Figs 5 and 6, overleaf). There is no extension to the iris root or the angle.

There is a third tumour present in this eye. It lies in the posterior third of the globe and covers the optic disc. Pigmentation and cell types are variable, mixed spindle and epithelioid cells are present, and vascularity is prominent (Fig. 7, overleaf). There is evidence of extension into the sclera along the posterior ciliary nerves as well as into the optic nerve and along the meninges. The retina has undergone extensive detachment except for the central dome of the tumour where it remains adherent. Secondary degenerative changes are present. No rupture of the retina can be seen. Subretinal serous exudative fluid contains pigment-laden macrophages. The vitreous contains no pigmented elements. The lens shows evidence of posterior synechiae.

\section{Comment}

This eye was sectioned completely. All three tumours, which were melanomatous in character, appeared to have independent origins and showed different histology. 


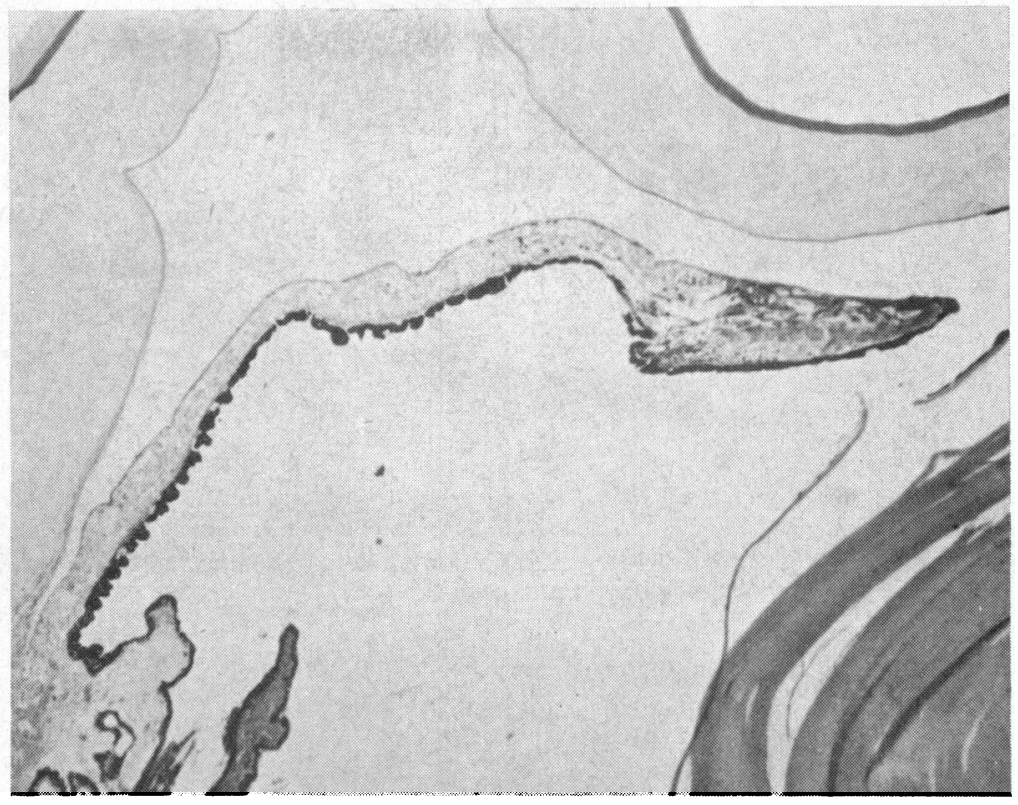

FIG. 5.-Benign melanoma seen at 3 o'clock. Haematoxylin and eosin. $\times 12 \cdot 5$.

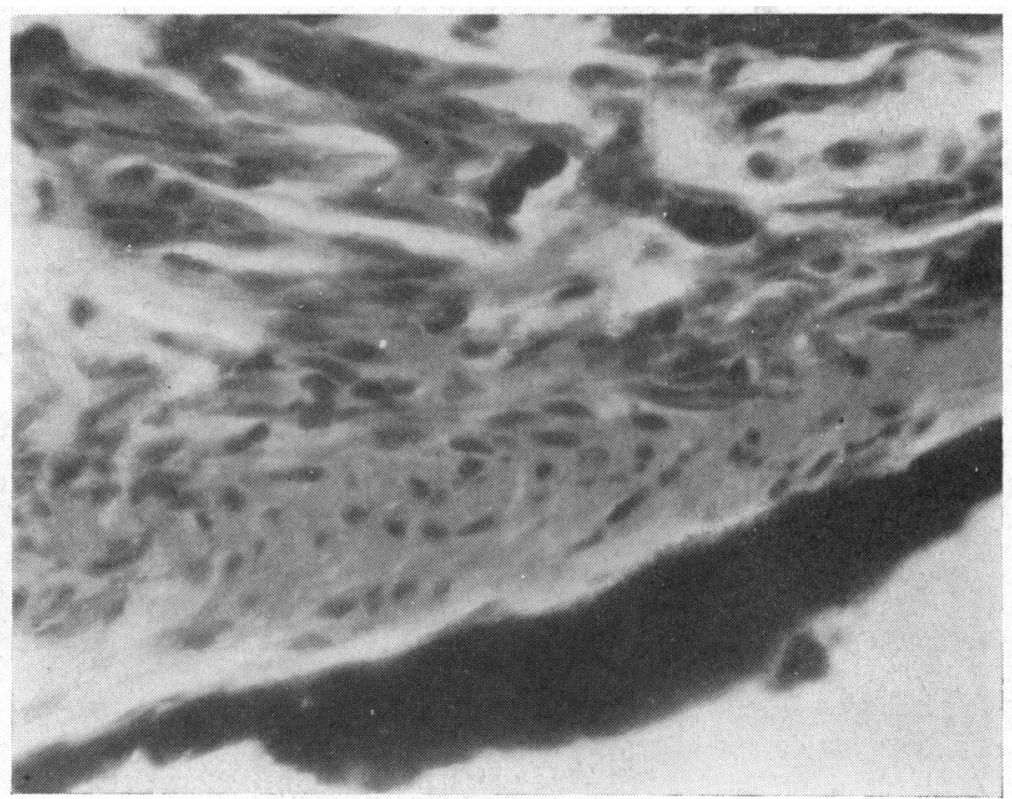

Fig. 6.-As in Fig. 5, demonstrating anterior situation and cell type above muscle. Haematoxylin and eosin. $\times 225$.

The eye contained:

(1) A benign melanoma localized to the sphincter muscle area;

(2) A melanoma extending from the iris to involve the angle and ciliary body;

(3) A large posterior choroidal mixed-cell malignant melanoma.

No evidence of continuity or mode of spread could be demonstrated. The 
Fig. 7.-Malignant melanoma from posterior choroid, showing epithelioid type of cell. Haematoxylin and eosin. $\times 225$

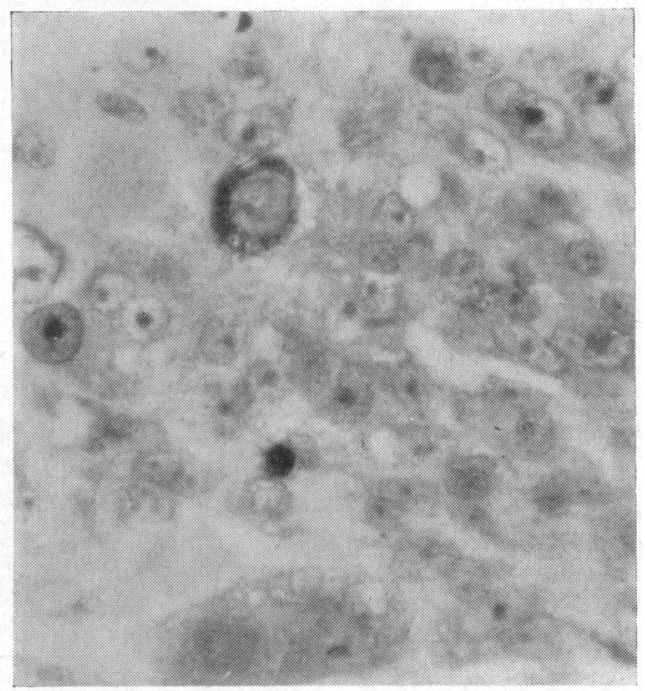

retina appeared to be unbroken and no pigment-laden macrophages were found in the vitreous. It was considered that there were three separate tumours present, two of them being malignant.

\section{Summary}

Two cases of multiple malignant melanomata have been previously reported with detailed pathological examination. A further example of multifocal malignant melanomata in a single eye is reported above.

\section{REFERENCES}

Frayer, W. C. (1956). A.M.A. Arch. Ophthal., 56, 160.

Hogan, M. J., and Zimmerman, L. E. (1962). "Ophthalmic Pathology", 2nd ed., p. 143. Saunders, Philadelphia.

ReEse, A. B. (1956). "Atlas of Tumor Pathology", Sect. X, Fascicle 38: "Tumors of the Eye and Adnexa", p. 96. Armed Forces Institute of Pathology, Washington, D.C. (1963). "Tumors of the Eye", 2nd ed., p. 251. Hoeber, New York.

Rosen, D. A., and Moulton, G. N. (1953). Amer. J. Ophthal., 36, 73. 